\title{
Los avances científicos como derecho humano de tercera generación en tiempos de pandemia
}

\section{Scientific advances as a third-generation human right in times of pandemic}

\author{
DOI: https://doi.org/10.17981/juridcuc.18.1.2022.03
}

Fecha de Recepción: 2021/06/01 Fecha de Aceptación: 2021/07/19

\author{
María Cristina Ramírez Castiblanco $\odot$ \\ Escuela Superior de Guerra (Colombia) \\ cristal0024@hotmail.com
}

Para citar este artículo:

Castiblanco, M. (2022). Los avances científicos como derecho humano de tercera generación en tiempos de pandemia. Jurídicas CUC, 18(1), 53-84. DOI: http://dx.doi.org/10.17981/juridcuc.18.1.2022.03

\section{Resumen}

La pandemia ocasionada por el virus Covid-19 ha puesto en jaque a la humanidad obligando al mundo entero a implementar medidas de distanciamiento y aislamiento social afectando la economía del planeta y la salud pública. Las grandes farmacéuticas financiadas, en muchas ocasiones, con dinero público se envolvieron en una carrera desbocada por conseguir una vacuna que pudiera regresar al planeta a la añorada normalidad dejando de paso sus arcas llenas. En el presente trabajo se analizan las consecuencias de impedir la liberación de la patente de esta vacuna con relación al derecho humano al uso de los avances de las ciencias y la tecnología. Empleando una metodología cualitativa, con un alcance descriptivo, basada en la revisión sistemática, bibliográfica y documental de la literatura, se evidencia la contraposición que se presenta entre los derechos de los pueblos a recibir la vacuna contra el Covid-19, como parte del derecho al uso de los avances de la ciencia y la tecnología en su calidad de derecho humano de tercera generación, y los intereses de las grandes empresas farmacéuticas y conglomerados empresariales privados, a la luz del Derecho, la ética y la salud pública, discerniendo sobre un tema controvertido que tiene en vilo a la humanidad. Se concluye que lo que está en juego va más allá de los intereses económicos, pues quienes posean y mantengan la propiedad de las patentes tendrán ventaja en términos de geopolítica y, de paso, mayor control sobre la biopolítica.

Palabras clave: Derechos humanos; pandemia; derecho a la salud; patente; vacunación

\begin{abstract}
The pandemic caused by the Covid-19 virus has pose a threat to humanity, forcing the entire world to implement measures of distancing and social isolation and has been a terrible blow to the planet's economy and public health. Large pharmaceutical companies around the world financed, on many occasions, with public money, were braided in a runaway race to get a vaccine that could return the planet to the hoped normality, leaving their coffers full. This paper analyzes the consequences of preventing the release of the patent for this vaccine in relation to the human right to use advances in science and technology. Using a qualitative methodology, with a descriptive, correlational and explanatory scope, based on a review of the literature, the opposition that occurs between the rights of peoples to receive the Covid-19 vaccine, as part of the right to use, is evidenced. of the advances of science and technology in its capacity as a third generation human right, and the interests of large pharmaceutical companies and private business conglomerates, in the light of Law, ethics and public health, discerning on a controversial issue that has humanity in suspense. It is concluded that what is at stake goes beyond economic interests, since those who own and maintain ownership of patents will have an advantage in terms of geopolitics and, incidentally, greater control over biopolitics.
\end{abstract}

Keywords: Human rights; pandemic; right to health; patent; vaccination 


\section{INTRODUCCIÓN}

Al terminar la Segunda Guerra Mundial ante un panorama desolador y al constatar que se habían cometido todo tipo de vejámenes y actos abominables en dicha confrontación la Asamblea General de las Naciones Unidas aprobó la Declaración Universal de los Derechos Humanos (ONU, 1948), con una genealogía de hitos históricos como la Declaración de Independencia de Estados Unidos (1776) y la Declaración de los Derechos del Hombre (1789). Esta Declaración "fue el primer documento legal en establecer la protección universal de los derechos humanos fundamentales" (ONU, 2021, p. 1), es decir los derechos básicos y fundamentales que detenta toda persona por el simple hecho de ser humano, como por ejemplo el derecho a la vida, a la libertad, a la igualdad ante la ley, por señalar algunos.

A medida que ha ido transcurriendo el tiempo la lista de estos Derechos Humanos (civiles y políticos, conocidos como Derechos Humanos de primera generación) ha ido acrecentándose para incluir dos grupos adicionales de derechos, primero, unos derechos de tipo colectivo (sociales, económicos y culturales, denominados de segunda generación) que procuren mejores condiciones de vida para las personas y, más recientemente, los llamados Derechos de los Pueblos o de Solidaridad (paz, desarrollo, y medio ambiente), los cuales responden a la necesidad urgente de que los países y de los pueblos cooperen entre sí para reivindicar garantías, individuales y colectivas, que cada vez resultan más necesarias para la vida digna de los seres humanos (Fischer-Lescano \& Möller, 2012).

Dentro de esta última generación de derechos humanos está, por ejemplo, el derecho a la paz, al medio ambiente, y al uso de los avances de las ciencias y la tecnología, entre otros. Este último es de gran relevancia en el caso presente ya que inmerso en este se inscribe el tema que da razón a esta investigación, pues dentro de los derechos que tienen los pueblos está el de poder hacer uso de los avances en ciencia y tecnología que la humanidad va 
logrando, especialmente cuando se trata de una situación de salud pública que afecte al grueso de la población, como es el caso de la pandemia por Covid-19, que pone en peligro inminente de muerte a millones de seres humanos.

A pesar de que las vacunas actualmente se están produciendo presentando altísimos índices de eficacia (en algunos casos del 90-95\%), sin embargo, debido a burocracia, a la ambición y a la falta de voluntad para liberar sus patentes se permite que mueran miles de personas al día (Johns Hopkins University of Medicine, JHU, 2021). Al respecto se presenta un choque de trenes entre los aspectos puramente legales y éticos, de un lado defendiendo gigantescos intereses económicos y del otro defendiendo la vida misma, con argumentos válidos de parte y parte como se analizará en el desarrollo de este trabajo, mientras el virus sigue pendiendo como la espada de Damocles sobre el destino de la humanidad al haber aparecido ya variantes y mutaciones del mismo.

Adicional a la crisis económica actual que ha refrenado el ímpetu del capitalismo rampante dejando a miles en la calle y arruinando a grandes, medianas y pequeñas empresas, el mundo viene experimentando de tiempo atrás una enorme desigualdad económica, fácilmente evidenciada al considerar que el 1\% de la población del mundo posee más riqueza que el restante 99\% (Oxfam International, 2020), separando al mundo en dos grupos: uno conformado por un puñado de países solventes y otro compuesto por muchos países con una economía precaria con graves problemas y grandes carencias. Lo anterior redunda en la situación que se está viviendo actualmente en la cual las grandes potencias han comprado lotes de vacunas suficientes para inmunizar tres, cuatro y hasta cinco veces a toda su población y están negociando aún más vacunas, mientras que los países llamados eufemísticamente "en vías de desarrollo" no pueden hacerse a éstas (ONU, 2021), bien sea porque no cuentan con los recursos económicos o bien porque los laboratorios ya las tienen apartadas y negociadas y se presenta carencia. 
A la tragedia anterior se suma el hecho de que los productores de las vacunas a pesar de haber sido financiados con ingentes cantidades de dinero público (Amnistía Internacional, 2021) no permiten la liberación de las patentes de las vacunas, anteponiendo el interés económico a la salud pública y pasando por alto el derecho humano de tercera generación al uso de los avances de las ciencias y la tecnología (García y Reyes, 2014; García, 2012; Golçalves, 2020). Mientras esto sucede hasta la fecha han muerto más de dos millones de personas en el mundo por Covid-19 y hay más de 111 millones de personas infectadas y aunque el virus no discrimina por clase social, los que más probabilidad tienen de morir en caso de infección son los pobres (Wallace, 2020; Pinilla, Ramírez y González, 2020; Jaramillo, 2021). De no liberarse las patentes de las vacunas se perderán millones de vidas más, transgrediendo un derecho humano de tercera generación y se estará atentando contra la salud mundial, ya que como lo recuerda la Organización de los Estados Americanos (OEA, 2021): "Ningún país estará a salvo hasta que todos lo estén" (p. 5). Es un tema de humanidad, sí, pero también de sentido común y de Derecho.

El presente trabajo de investigación pone evidencia la contraposición que se presenta entre los derechos de los pueblos a recibir la vacuna contra el Covid-19, especialmente aquellos con mayores problemas sociopolíticos y políticos dentro de los que se encuentra los africanos y latinoamericanos, en general, y Colombia en particular, y los intereses de las grandes empresas farmacéuticas y conglomerados empresariales privados, a la luz del Derecho, la ética y la salud pública.

\section{Metodología}

Metodológicamente hablando, para el desarrollo del presente trabajo se recurre al paradigma cualitativo empleando un enfoque de tipo hermenéutico que permita un alcance descriptivo de la información, a la cual se llegó a través de una revisión sistemática, bibliográfica $\mathrm{y}$ documental de la literatura pertinente. 


\section{Resultados - Discusión}

\section{Derechos humanos y su clasificación por generaciones}

En primer lugar, es conveniente hacer una aproximación conceptual con referencia a los derechos humanos de tercera generación. Se puede considerar que lo que actualmente se denomina como derechos humanos tienen sus orígenes primeros en pleno auge del primer gran imperio mundial, los Persas o también llamados pueblo Medo, y es el Ciro II, el Grande, quien dio las primeras muestras de reconocimiento de unos derechos connaturales al ser humano que no se le debían arrebatar, así quedó registrado en los anales de la historia cuando se menciona la conquista por parte suya y de sus ejércitos a Babilonia, donde libertó a los hasta ese momento esclavos babilonios diciéndoles que eran libres de escoger el credo religioso que quisieran y estableciendo una semi-equidad racial, situaciones muy interesantes y singulares si consideramos que se está hablando de hechos sucedidos hace más de 2500 años quedando registrados mediante escritura cuneiforme en las tablillas de arcilla que han llegado hasta estos días, permitiendo su conocimiento (Moyn y Jácome, 2015).

Sin embargo, hechos como el citado han sido la excepción a la regla y han pasado muchos años para un reconocimiento global de los derechos humanos y de sus tres generaciones. Los actuales derechos humanos se pueden considerar como el desarrollo o la evolución de aquellos primeros concebidos por el movimiento libertario políticocientífico-cultural conocido como la Ilustración y propagados hacia el mundo desde Francia en la época de su Revolución, 1789.

Hay que decir que realmente es inaudito que antes de esta época de transición entre la edad moderna y la contemporánea la humanidad no hubiera acordado establecer unos derechos básicos y fundamentales que cobijaran a toda la población y dignificaran su diario vivir. Sin embargo, es cierto que no fue sino hasta entonces que una pequeña élite francesa entre quienes se contaban Diderot, D’alembert, Marat, Montesquieu y otros más, se dio a la tarea de reivindicar una existencia digna para sus congéneres con unos estándares básicos que todos debían acatar y respetar (Rodríguez, 2015); dando lugar, de 
paso, a conceptos novedosos en ese momento y ahora considerados fundamentales en los países democráticos, como división de poderes y libertad de cultos, sentando las bases para el nacimiento del derecho administrativo y proteger a los individuos de los excesos que pueda cometer el Estado, y se propuso acabar con el feudalismo y las prerrogativas de clero y nobleza, entre otras muchas cosas.

Esta proclama y reivindicación de los derechos de los hombres y los ciudadanos fue además la fuente de la cual bebió la organización que actualmente se denomina Organización de las Naciones UnidasONU para en el año 1948, poco después de terminada la Segunda Guerra Mundial, publicar la Declaración Universal de los Derechos Humanos, conformada entonces por 30 artículos, apuntando en su preámbulo:

Nosotros los pueblos de las Naciones Unidas resueltos:

A preservar a las generaciones venideras del flagelo de la guerra que dos veces durante nuestra vida ha infligido a la Humanidad sufrimientos indecibles,

A reafirmar la fe en los derechos fundamentales del hombre, en la dignidad y el valor de la persona humana, en la igualdad de derechos de hombres y mujeres y de las naciones grandes y pequeñas,

A crear condiciones bajo las cuales puedan mantenerse la justicia y el respeto a las obligaciones emanadas de los tratados y de otras fuentes del derecho internacional,

A promover el progreso social y a elevar el nivel de vida dentro de un concepto más amplio de la libertad (ONU, 1945, p. 1).

Reconociendo en este introito que se había estado en mora durante mucho tiempo con la humanidad entera para resarcir y vindicar derechos que le son connaturales por el sólo hecho de haber nacido humano y que le equiparan en dignidad con todos sus semejantes. Estos derechos, como lo indica su nombre, tienen la calidad de ser universales además de inalienables, interdependientes, promoviendo la igualdad, la equidad, la no discriminación, a la vez que fomentan la participación e inclusión. Esta Declaración de los Derechos Humanos 
hizo eco, además, al dolor y espanto que habían producido dos guerras mundiales en menos de medio siglo con millones de bajas humanas y el sufrimiento directo de todos los países involucrados.

Cabe señalar que estos derechos humanos en la actualidad son reconocidos y han sido signados por la mayoría de países del mundo, sin embargo, el respeto de los mismos en gran medida es facultativa de los países y, en este punto, resulta pertinente distinguir entre derechos humanos y derechos fundamentales, términos con los que se ha presentado ambigüedad y que a pesar de emplearse como sinónimos no lo son pues tienen diferente alcance. Mientras que se ha concedido que los derechos humanos le son atribuibles a todas las personas por el hecho de ser humanos, teniendo así un alcance universal, los derechos fundamentales son reconocidos por la Constitución de un país alcanzando así un alcance regional. De esta manera, por ejemplo, el derecho humano a la salud tiene un reconocimiento cobijado por instrumentos internacionales, mientras que no es derecho fundamental pues puede variar dependiendo del país.

Es así que los derechos fundamentales están subsumidos dentro de los derechos humanos como enfatiza González (2018):

Para que exista un derecho fundamental, con anterioridad debe existir un derecho humano, por ende, un derecho fundamental es una garantía que brinda la nación a todo individuo que está dentro de su límite territorial, que se ve regido por una carta magna, y que dota de facultades que deben gozar plenamente todo individuo dentro de un territorio nacional (párr. 16).

De manera que aunque en múltiples ocasiones son coincidentes el principal baremo para diferenciarlos sería el territorio de aplicación, siendo universales en el primer caso y vinculados a la constitución nacional de cada país en el segundo caso. No obstante que en los medios masivos de comunicación se escucha frecuentemente hablar de violación de derechos humanos, éstos continuando siendo el último bastión de la dignidad y el respeto de los humanos por parte de ellos mismos. 
Ahora bien, con el transcurrir del tiempo ha ido surgiendo la necesidad de reconocer derechos adicionales a aquellos primeros que poseían un carácter netamente político y civil, apareciendo entonces la valoración de otros derechos de carácter económico, social y cultural, y más recientemente acorde con los tiempos que se viven, el reconocimiento de derechos ecológicos y de solidaridad. Es así que se ha presentado una clasificación de los derechos humanos en tres generaciones con base en el avance de la cobertura que han tenido. A continuación, se analiza cada uno de estos.

\section{- Derechos de primera generación}

Como ya se mencionó los primeros derechos humanos reconocidos correspondían a libertades fundamentales de carácter civil y político y le corresponden al individuo frente al Estado o frente a cualquier autoridad, son los denominados Derechos Humanos de Primera Generación, que tienen su sustento filosófico, político y social tanto en la Declaración de Independencia de Estados Unidos de América, en 1776, y la Carta de Derechos (Bill of Rights) de 1791, como en la Revolución Francesa de 1789 y tenían como objetivos principales limitar el poder del Estado sobre sus ciudadanos y asegurar la participación de éstos en la política de sus países.

Estos derechos de primera generación tienen que ver directamente con las posibilidades del ser humano para disfrutar de atribuciones tales como, en primer lugar, la vida, y, en segundo lugar: "la propiedad, la libertad, la igualdad, la seguridad, la capacidad para expresar su opinión, organizarse políticamente, designar a sus gobernantes por medio del voto, etcétera" (Bailón, 2009, p. 109).

Algunos autores, entre ellos Gómez (2004) y Sánchez (2001) proponen una subdivisión de esta primera generación en derechos civiles individuales (derecho a la vida, a la libertad, a la propiedad y a la seguridad) y en derechos políticos o de ejercicio colectivo (derecho al voto, a la libertad de reunión y de imprenta). No obstante lo anterior, desde una perspectiva histórica estos dos grupos de derechos corresponden con el Estado liberal de derecho. 


\section{- Derechos de segunda generación}

Los derechos humanos de segunda generación fueron concebidos desde finales del siglo 19 y todo el siglo 20, mientras que los de primera generación defendían principalmente el valor de la libertad, los de segunda generación se enfocan más en la igualdad entre las personas como condición para que puedan desarrollar sus capacidades y llevar una vida digna, acorde con la coyuntura histórica que pasaba el mundo en esta época; abarcan los derechos económicos, sociales y culturales y la responsabilidad del Estado para que todos los ciudadanos tengan acceso a éstos.

Dentro de los derechos de segunda generación se pueden mencionar el derecho a la salud, a la educación, a una vivienda digna, al trabajo, entre otros. Su reconocimiento oficial ocurrió en el Pacto Internacional sobre Derechos Económicos, Sociales y Culturales, adoptado por la Organización de las Naciones Unidas en 1966, entrando en vigor diez años después, en 1976. El Consejo de Europa en su Manual de Educación en los Derechos Humanos con jóvenes (COE, 2015) los reivindica al afirmar:

Estos procesos [la industrialización y el aumento de la clase obrera] dieron lugar a la aparición de nuevas demandas e ideas acerca del significado de la vida y la dignidad humana. Se dieron cuenta de que la dignidad de la persona humana exige algo más que la mínima falta de interferencia por parte del estado, propuesta por los derechos civiles y políticos. Los derechos económicos, sociales y culturales están recogidos en el Pacto Internacional de Derechos Económicos, Sociales y Culturales (PIDESC) y también en la Carta Social Europea del Consejo de Europa (p. 430).

Con ellos se pretende ayudar a construir una sociedad no tan desigual a la par que disminuir la brecha entre ricos y pobres, situaciones que conllevan a inequidad, falta de oportunidades, insatisfacción, entre otras; debe quedar claro que no se pretende que todos tengan los mismos bienes pues resultaría utópico sino, más bien, crear las condiciones para que la gran mayoría de seres humanos puedan contar con unos derechos socioeconómicos y culturales básicos para 
el desarrollo personal digno, ayudando a su vez a que se cumplan los derechos humanos de primera generación. Es decir, y resumiendo lo planteado, los derechos humanos de segunda generación tienen como titular de los mismos a la comunidad que decide agruparse para defender sus aspiraciones legítimas en cuanto a prestación de servicios y satisfacción de necesidades.

Desde la jurisprudencia estos derechos se pueden considerar positivos en la medida que obligan a unas acciones como lo son, en este caso, la satisfacción de necesidades y la prestación de servicios.

\section{- Derechos de tercera generación}

Estos derechos emergieron a la luz desde finales del siglo $20 \mathrm{y}$ principios del 21, como en los casos anteriores respondiendo a las necesidades que iban surgiendo o que se hacían más apremiantes durante esta época, buscando reivindicar los derechos a la justicia, a la paz y a la solidaridad, a través de la promoción de relaciones constructivas y pacíficas que hagan posible hacer frente a los retos, tanto nuevos como a aquellos que se han ido agudizando con el paso del tiempo, a los que los seres humanos deben enfrentarse para su subsistencia en el planeta y para el bienestar de las generaciones futuras.

Son conocidos como derechos de los pueblos, derechos colectivos, derechos emergentes o derechos de solidaridad (Cassagne, 2019) pues representan un interés común de una colectividad y comprenden la paz, el desarrollo y el medio ambiente, siendo considerados desde el Derecho como derechos positivos en la medida que exigen hacer algo y también negativos en la medida que implican la inacción de ciertos hechos o actividades.

Estos derechos humanos de tercera generación surgen como resultado de la necesidad de hacer frente a problemas globales a partir de la cooperación entre pueblos, y dentro de ellos se pueden citar: el derecho a la paz, a la identidad nacional y cultural, a la autodeterminación, al medio ambiente, al patrimonio común de la humanidad, a la intimidad, entre otros. Algunos estudiosos del tema consideran que en realidad no son una nueva generación de derechos humanos 
sino que simplemente son la validación y reivindicación de los derechos humanos de primera y segunda generación, como puede ser el caso del derecho a la intimidad (Mendoza, Bechara y Caballero, 2021).

Aquí vale la pena señalar que recientemente se ha propuesto incluir una cuarta generación de derechos humanos que involucren el desarrollo de la tecnología y la información y el acceso a los mismos, pudiéndose mencionar dentro de estos el derecho a la información, al pluralismo y a la democracia. No obstante, actualmente sigue siendo apenas una propuesta en consideración.

A continuación, en la Tabla 1 se compendian las principales características de cada una de las generaciones de derechos humanos analizados.

TABLA 1.

Principales características de las generaciones de los derechos humanos.

\begin{tabular}{|c|c|c|c|c|}
\hline Generación & Siglos & $\begin{array}{c}\text { Valor } \\
\text { principal }\end{array}$ & $\begin{array}{l}\text { Tipo de } \\
\text { derecho }\end{array}$ & Función \\
\hline Primera & $18-19$ & Libertad & $\begin{array}{l}\text { Civiles y } \\
\text { políticos }\end{array}$ & $\begin{array}{l}\text { Velar porque no haya } \\
\text { excesos de poder y } \\
\text { porque los ciudadanos } \\
\text { puedan participar en } \\
\text { política. }\end{array}$ \\
\hline Segunda & $19-20$ & Igualdad & $\begin{array}{l}\text { Económicos, } \\
\text { sociales y } \\
\text { culturales }\end{array}$ & $\begin{array}{l}\text { Asegurar que los } \\
\text { ciudadanos puedan } \\
\text { disfrutar una vida } \\
\text { digna. }\end{array}$ \\
\hline Tercera & $20-21$ & Solidaridad & $\begin{array}{l}\text { Justicia, paz } \\
\text { y solidaridad }\end{array}$ & $\begin{array}{l}\text { Fomentar un entorno } \\
\text { pacífico, constructivo y } \\
\text { adecuado. }\end{array}$ \\
\hline $\begin{array}{l}\text { Cuarta (en } \\
\text { consideración } \\
\text { actualmente) }\end{array}$ & 21 & Equidad & $\begin{array}{l}\text { Informático } \\
\text { y tecnológico }\end{array}$ & $\begin{array}{l}\text { Promover que la } \\
\text { información y la } \\
\text { tecnología sean para } \\
\text { todos. }\end{array}$ \\
\hline
\end{tabular}

Fuente: Adaptado de Instituto Nacional de Tecnologías Educativas y de Formación del Profesorado (INTEF, 2015).

En la Tabla 2 se describen los derechos humanos que conforman cada una de las tres generaciones consideradas. 
TABLA 2.

Listado de los derechos humanos que componen cada generación.

\begin{tabular}{|c|c|c|c|}
\hline \multicolumn{4}{|c|}{ Derechos Humanos } \\
\hline $1^{a}$ generación & $2^{\mathrm{a}}$ generación & $3^{a}$ generación & $4^{\mathrm{a}}$ generación \\
\hline $\begin{array}{l}\text { - Todo ser humano tiene derechos y libertades } \\
\text { fundamentales independiente de cualquier } \\
\text { consideración. } \\
\text { - Todo individuo tiene derecho a la vida, a la } \\
\text { libertad y a la seguridad jurídica. } \\
\text { - Los derechos son iguales para todos } \\
\text { independiente de su género. } \\
\text { - Nadie debe soportar esclavitud. } \\
\text { - Ningún ser humano debe recibir tratos } \\
\text { inhumanos ni degradantes, tampoco tortura } \\
\text { ni daño físico, psíquico ni moral. } \\
\text { - La honra y/o reputación son inalienables. } \\
\text { - Los seres humanos tienen derecho a la libre } \\
\text { circulación. } \\
\text { - La nacionalidad es un derecho humano básico. } \\
\text { - En caso de persecución política, toda persona } \\
\text { tiene derecho a buscar asilo. } \\
\text { - Derecho a casarse y a tener hijos. } \\
\text { - Los seres humanos tienen derecho a elegir } \\
\text { su religión y a expresar su pensamiento } \\
\text { libremente. } \\
\text { - El ser humano tiene derecho a opinar. } \\
\text { - Nadie puede prohibir que las personas se } \\
\text { reúnan y asociación de manera pacífica. }\end{array}$ & $\begin{array}{l}\text { - Es derecho del hombre disponer } \\
\text { de seguridad social y disfrutar de } \\
\text { derechos económicos, sociales y } \\
\text { culturales. } \\
\text { - Toda persona tiene derecho a tener } \\
\text { un trabajo bajo unas condiciones } \\
\text { equitativas y satisfactorias. } \\
\text { - El ser humano tiene derecho a } \\
\text { defender sus intereses laborales } \\
\text { a través de la formación de } \\
\text { sindicatos. } \\
\text { - Toda persona debe poder asegurar } \\
\text { la vida digna de su familia (salud, } \\
\text { alimentación, vestido, vivienda, } \\
\text { asistencia médica). } \\
\text { - La salud física y mental adecuadas } \\
\text { no son un lujo, son un derecho que } \\
\text { tiene toda persona. } \\
\text { - La etapa de la infancia y de la } \\
\text { maternidad gozan del privilegio de } \\
\text { asistencia y cuidados especiales. } \\
\text { - La educación básica es un derecho } \\
\text { que debe tener todo ser humano. }\end{array}$ & $\begin{array}{l}\text { - El ser humano tiene derecho } \\
\text { a usufructuar los avances en } \\
\text { ciencias y tecnología. } \\
\text { - De igual manera el ser } \\
\text { humano tiene el derecho a los } \\
\text { desarrollos que le otorguen } \\
\text { una vida digna. } \\
\text { - Los humanos tienen derecho } \\
\text { a tener independencia } \\
\text { económica, a la } \\
\text { autodeterminación, a la } \\
\text { identidad cultural y nacional. } \\
\text { - La coexistencia pacífica, la } \\
\text { cultura, así como la solución } \\
\text { de problemas demográficos y } \\
\text { ecológicos (medio ambiente) } \\
\text { son derechos de los que debe } \\
\text { gozar todo ser humano. } \\
\text { - La cooperación internacional } \\
\text { y la justicia internacional son } \\
\text { derechos, no lujos. } \\
\text { - El patrimonio común de la } \\
\text { humanidad. }\end{array}$ & $\begin{array}{l}\text { - Derecho a } \\
\text { conocer, tener } \\
\text { acceso y hacer } \\
\text { uso de las nuevas } \\
\text { tecnologías. } \\
\text { - Derecho al } \\
\text { Habeas Data } \\
\text { (que los datos } \\
\text { propios estén } \\
\text { actualizados) y } \\
\text { a la seguridad } \\
\text { digital. } \\
\text { - Derecho al uso } \\
\text { del espectro } \\
\text { radioeléctrico y de } \\
\text { la infraestructura } \\
\text { para los servicios } \\
\text { en línea. }\end{array}$ \\
\hline
\end{tabular}

Fuente: Adaptado de Comisión Nacional de los Derechos Humanos (CNDH, 2015). 
En este punto es oportuno llamar la atención sobre un tema que resulta primordial en el caso de la segunda y tercera generación de los derechos humanos y es el de falta de carácter vinculante que presentan; resulta que se le ha venido dando prioridad a los derechos humanos civiles y políticos por sobre los de segunda generación (económicos, sociales y culturales) y a estos se les ha dado prioridad sobre los de tercera generación (justicia, paz y solidaridad), de manera que se le da mayor importancia y se acata en mayor medida a los que promulgan por el derecho fundamental a la libertad por sobre aquellos que representan la igualdad y la solidaridad.

Siendo así prima un mayor respeto por los derechos individuales por sobre los colectivos y este cisma no es sólo nominal, estuvo marcado por sendos tratados promulgados por la ONU, el primero se denominó el Pacto de Derechos Civiles y Políticos, el segundo, Pacto de Derechos Económico Sociales y Culturales, ambos en 1966. Este hecho, aunque sirvió para reivindicar derechos que antes se pasaban por alto, también dio paso a la separación entre derechos civiles, de una parte, y sociales, de otra, y a la subvaloración de unos frente a otros que se viene mencionando.

Este sistema de valores que se ha ido instalando, además consuetudinariamente, ha dado como resultado que los Estados den mayor prioridad al compromiso y cumplimiento de unos derechos por sobre otros, los cuales resultan igualmente importantes en la sociedad actual, como vienen siendo el derecho a la salud, a la educación, a la paz, a un ambiente sano, por citar algunos. Como se viene mencionando, a los que se les ha dado menor prioridad es precisamente a los derechos humanos de tercera generación y de cierta manera resulta curioso que actualmente son de una vigencia extraordinaria y son más que nunca necesarios en momentos de múltiples crisis a nivel global. Se está hablando de unos derechos que parecen de un carácter lógico apenas básico y los cuales también debería poseer todo ser humano por el simple hecho de serlo, por ejemplo: tener derecho a la autodeterminación, a la coexistencia pacífica, a la cooperación internacional y regional, al uso de los avances en ciencia y tecnología, este último motivo del presente trabajo. 
Sin embargo, como se puede apreciar con sólo mirar afuera, la realidad dista mucho de lo escrito, una gran parte de la población mundial no ostenta el usufructo de estos derechos y, en muchas ocasiones, tampoco los puede reclamar o, peor aún, no sabe que tiene derecho a éstos. En este caso es menester señalar, como lo hace Bidart (1996), que desde el punto de vista del Derecho a los DDHH de primera generación se les concede un carácter negativo, esto es que al Estado sólo se le pide con respecto a ellos que no interfiera de manera negativa en su cumplimiento, de manera que se apliquen directamente y que su cumplimiento se pueda exigir judicialmente. Mientras que a los DDHH de segunda y tercera generación se les otorga un carácter positivo al necesitar para su cumplimiento de la participación positiva del Estado y, en este orden de ideas, se hace muy complicado que se puedan exigir directamente (Bonet, 2016); en el caso del Covid-19 el derecho a la salud es un derecho social que exige un "deber hacer" por parte del Estado para que se presenten las condiciones necesarias para su cumplimiento (Alé, 2021).

Aquí se cuestionaría, incluso, la pertinencia de la separación de los DDHH en generaciones y su división en civiles-político, económicos-sociales-culturales, y en derechos de los pueblos o de solidaridad, ya que esta segregación iría en contravía de los principios generales de los Derechos Humanos como lo son el de indivisibilidad y el de interdependencia, reconocidos en el Artículo 5 de la Declaración y Programa de Acción de Viena, firmada en 1993 en la Conferencia Mundial de Derechos Humanos (Oficina del Alto Comisionado de las Naciones Unidas para los Derechos Humanos-ACNUDH, 2013), pues el carácter de indivisibilidad impediría esta discriminación y el de interdependencia obligaría a que el cumplimiento de uno llevara al cumplimiento de los demás derechos, presentándose entonces una clara incoherencia.

La respuesta que dio el campo de la jurisprudencia y la legalidad fue subsumir los DHH de segunda y tercera generación dentro de los de primera generación. Esto se hizo proponiendo que tanto los derechos sociales, económicos y culturales como los derechos de 
los pueblos fueran concebidos como parte de los derechos civiles y políticos, es decir como anexos o accesorios de éstos, de modo que al cobijar los derechos civiles y políticos se salvaguardaban, de paso, todos los demás; esto solucionó el problema legal y nominal. Sin embargo, en la práctica, lavó las manos de la responsabilidad estatal y dejó sin cobertura a los considerados como derechos menores: los sociales y los de los pueblos, limitándose a exigir a los Estados los deberes de respetar, proteger y garantizar los derechos mayores.

Siendo este el caso, se presenta una especie de aporía pues en el papel se señala unas condiciones y en la práctica se cumplen otras, ya que en el caso de los DDHH de segunda y tercera generación en gran medida su cumplimiento es potestativo de cada Estado y discrecional, dependiendo de múltiples variables como las finanzas, la voluntad política, el sistema de gobierno imperante, esto a nivel local, pero también hay circunstancias internacionales como por ejemplo a las organizaciones que pertenezca el país, las normas a las que esté sujeto y, en consecuencia, las consecuencias que conllevaría incumplir tratados o pactos.

Ahora bien, como una posible solución a este dilema teóricopráctico ha surgido algunas opciones viables, dentro de las cuales se pueden subrayar, primero desde el Derecho, la opción de lo que se conoce como la justiciabilidad de los derechos humanos y con justiciabilidad el Instituto Interamericano de Derechos HumanosIIDH (2009) hace referencia a "(...) hacer justicia, y que en un modelo de legalidad se logra por una vía institucional, particularmente mediante los mecanismos judiciales" (p. 85). Añade la IIDH (2009):

La justiciabilidad busca la realización de un derecho por vía de su reclamación ante instancias que administran justicia (...) La justiciabilidad supone, por tanto, una pretensión formulada por un reclamo en contra de un sujeto obligado por el derecho y al mismo tiempo un ente decisor que, satisfechas determinadas circunstancias, resuelve la controversia (p. 85). 
Para el caso de este escrito la justiciabilidad para el cumplimiento del derecho humano al uso de los avances de las ciencias y la tecnología permitiría recurrir al sistema judicial en busca de protección del derecho no cumplido determinando, a la vez, responsabilidades y responsables, a través del debido proceso, buscando el cumplimiento del derecho y el resarcimiento a que haya lugar.

La segunda opción es la propuesta inicialmente por Van Hoof en 1984 y corresponde a la creación de una sola generación de derechos humanos, eliminando la división en generaciones y, más bien, clasificando las obligaciones del Estado en línea con la totalidad de estos derechos, independiente de si son civiles, sociales o de solidaridad, de manera que el Estado estaría obligado a respetar, proteger, realizar y promover todos los derechos de igual manera (Nikken, 2010).

No obstante, la opción de la justiciabilidad y la de unicidad de los DDHH aún están en debate y continúan siendo motivo de análisis, críticas y debates por las instituciones internacionales legalmente encargadas, por profesionales del Derecho y por la academia quienes siguen de cerca el posible devenir de estas propuestas.

Recapitulando lo visto en este acápite se concluye que este desglose de los derechos humanos en generaciones se corresponde con los momentos históricos en los cuales han surgido respondiendo a necesidades que se han ido haciendo evidentes con respecto a una mejor calidad de vida de la humanidad. De esta manera la primera generación responde a derechos civiles y políticos, la segunda a derechos económicos, sociales y culturales, y la tercera a intereses comunes que afectan a colectividades o grupos de personas.

Recientemente con el auge de las tecnologías de la información y la comunicación y de la tecnología en general se ha puesto a consideración una cuarta generación que correspondería a derechos humanos vinculados al desarrollo tecnológico, al ciberespacio y a la comunicación. Es importante reseñar que esta clasificación no corresponde a una jerarquía o prevalencia de unos sobre otros y los países están en obligación de hacerlos respetar y valer de la misma manera. 


\section{La vacuna para Covid-19}

Básicamente a partir de la segunda revolución industrial, con el advenimiento de la electricidad, y durante la tercera revolución industrial con el nacimiento y auge de los sistemas informáticos el mundo fue testigo del asombroso desarrollo que tuvieron la ciencia y la tecnología permitiendo mejorar la calidad de vida de la población y augurando un futuro antropocéntrico a corto plazo en el cual el hombre prevalecía en el planeta y dominaba el entorno y la naturaleza. Fue así como, por ejemplo, con el descubrimiento de la penicilina en 1928 por parte de Fleming, se pudieron salvar millones de vidas (y se siguen salvando) al poderse tratar las enfermedades de origen infeccioso, la medicina tuvo un avance prodigioso al poderse tratar muchas enfermedades antes letales y el ser humano pensó haber triunfado en este campo (Lolas, 2020; Castro, Cagüeñas, Quintero, Frenández y Silva, 2020).

No obstante, los virus siguen dando sorpresas y, es así como en los albores del siglo 21 aparecen los coronavirus, especialmente el Covid-19, causando estragos y llevando al mundo a una pandemia y devolviéndolo a épocas previas de aislamientos sociales y cuarentenas afectando negativamente la vida económica, social, cultural, etc.

Dentro de los derechos humanos de tercera generación se mencionó el derecho al uso de los avances de las ciencias y la tecnología, dentro de los cuales se podrían contar los medicamentos que hagan posible hacer frente a pandemias que pongan en riesgo la salud de la humanidad entera, situación esta última que hasta hace menos de año y medio era puramente hipotética y era motivo solamente de guiones de películas apocalípticas, de un momento a otro se materializó y se convirtió en el día a día de millones de personas con la aparición del coronavirus SARS-CoV-2, más conocido mundialmente como Covid-19.

Rememorando un poco, la situación no fue totalmente intempestiva pues la familia de coronavirus ya había dado avisos de su aparición previamente con cepas menos agresivas y generalizadas 
como fue el caso del Síndrome Respiratorio Agudo Severo (SARS) y del Síndrome Respiratorio de Oriente Medio (MERS), los dos peligrosos pero que no evolucionaron a pandemia. Los coronavirus, como señala la Organización Panamericana de la Salud-OPS son una familia de virus que ocasionan enfermedades en animales y en humanos, en estos últimos afectando principalmente al sistema respiratorio, produciendo desde resfriados comunes hasta enfermedades potencialmente letales como el Covid-19 (OPS, 2020), esta última ocasionando desde su aparición hasta mayo de 2021 cerca de 153 millones de casos confirmados y alrededor de tres millones de muertes (Statista, 2021).

En respuesta, las grandes corporaciones farmacéuticas se dieron a la tarea de concebir y fabricar una vacuna que pudiera detener al virus y a las muertes consecuentes, es así como varios laboratorios han logrado producir diversas vacunas con alta efectividad en el mínimo tiempo posible y como el enemigo a vencer no era solamente el virus sino también el tiempo la investigación ha sido financiada con grandes aportes del erario de varios países ya que se trata de una emergencia de salud pública mundial (Bonilla, 2020).

Sin embargo cuando finalmente se tienen las vacunas, los laboratorios los cuales pertenecen a grandes empresas farmacéuticas reclaman su propiedad sobre las patentes de las vacunas, convirtiendo un tema de salud pública mundial en un tema netamente económico. Sin tomar en cuenta los aportes públicos hechos durante la investigación y los temas éticos (se está hablando de corporaciones multinacionales con ingresos anuales de miles de millones de dólares sin contar ingresos por esta vacuna) y afectando los Derechos Humanos, entre ellos especialmente "el derecho a la ciencia, la tecnología y el saber científico, que garantiza el acceso a los conocimientos científicos, tecnológicos y humanísticos, y a beneficiarse de los resultados" (Instituto de Drets Humans de Catalunya-IDHC, 2009, art. 8).

Debe recordarse que las patentes son derechos de exclusividad que se conceden por parte de Estados o de organismos internacionales para la protección de un invento, por tanto, protegen a un producto 
para que no pueda copiarse y nadie más puede fabricarlo; esto que es absolutamente legal bajo la perspectiva del Derecho internacional corre el riesgo de terminar prestándose para un monopolio de precios y un encarecimiento de los productos, si no se maneja y normatiza adecuadamente.

A pesar de las iniciativas internacionales a través de programas puntuales liderados por la Organización Mundial de la Salud-OMS como "Covax" para llevar vacunas de manera gratuita a los países más desfavorecidos este programa no está funcionando y las grandes potencias mundiales están acaparando las vacunas para sí, provocando escasez de estas y disminuyendo drásticamente la posibilidad del resto de países de conseguirlas:

Si los países ricos no se comprometen casi en su totalidad, la consecuencia sería que aquellos estados sin recursos no podrían empezar a acceder a vacunas hasta 2023 mientras que los ricos se sientan sobre millones de dosis de vacunas sin inyectar, con toda su población para entonces ya cubierta (Trula, 2021, párr. 3).

Esta falta de atención a este derecho humano de tercera generación resulta más indignante al considerar que en las grandes potencias habita apenas un 16\% de la población mundial, pese a lo cual se han hecho a más de un 60\% de las dosis de vacunas (Marcus, 2021; Twohey, Collins y Thomas, 2020) y el 75\% de las vacunas producidas está dirigido a diez países, todos desarrollados y con altos ingresos. Por su parte, las farmacéuticas se escudan en el derecho internacional y esperan la opinión de organismos internacionales como la Organización Mundial del Comercio-OMC y la Oficina Europea de Patentes-OEP, impidiendo que la fabricación de la vacuna se lleva a cabo de manera democrática, global y a bajo costo.

En este caso las empresas farmacéuticas están apoyadas por los gobiernos de países ricos como Estados Unidos, Inglaterra y Suiza (precisamente en donde están radicadas la mayoría de las grandes farmacéuticas) quienes aducen que se deben respetar los derechos de propiedad intelectual de los medicamentos ya que el dinero así reunido es el que permite que continúe la investigación para desarrollar 
más medicamentos; todo esto sucede mientras diariamente mueren miles de personas a causa del virus en el mundo y otras tantas están fuera contagiándose, y, aunque la producción continúa, su alcance está lejos de llegar a una gran parte de la población.

Este panorama sería diferente si los DDHH de tercera generación tuvieran un carácter vinculante y fuera obligatorio liberar la patente de las vacunas contra la Covid-19 para responder al derecho a la salud y también al derecho al uso de los avances de la ciencia y la tecnología, sin embargo entramos al mundo de los supuestos y las hipótesis por la actual segregación debido a la importancia que se les da a unos derechos sobre otros. Entonces ¿qué se podría hacer? Como se mencionó, haría falta positivizar la segunda y tercera generaciones de derechos humanos, para que al serles reconocidos su carácter de consagrados puedan ser exigibles por parte de sus titulares, bien sea a nivel individual o colectivo, con reconocimiento a nivel mundial pero también con carácter vinculante en los ordenamientos jurídicos de cada Estado.

No obstante, aunque el camino a recorrer para pasar de normas no vinculantes a derechos vinculantes es largo y lleno de complicaciones pues requeriría un consenso general y compromisos y apoyos de todos los Estados principalmente a nivel económico, aunque también a los niveles político, jurídico y social, es necesario transitarlo y cuanto antes, mejor, para responder a las necesidades urgentes de la humanidad que permitan una vida digna cada vez con mayor necesidad de basarse en la solidaridad, en la medida que ésta es, como declaraba la poetisa Gioconda Belli, muestra de la ternura de los pueblos y uno de los últimos resquicios en los que buscar protección y amparo.

En este trayecto hacia el reconocimiento de los DDHH de tercera generación como derechos fundamentales hay países de Suramérica que han logrado avances notables, al menos nominalmente, al incorporarlos en sus constituciones nacionales, como Nicaragua en 1987, reconociendo, por ejemplo, el derecho al desarrollo y a la autodeterminación de los pueblos; Venezuela en 1999 al reconocer el derecho a la protección del patrimonio cultural y artístico de la 
humanidad, Brasil en 1988 con la defensa de la paz y la cooperación entre pueblos, Argentina en 1994 reconoce el derecho a proteger el ambiente, entre otros (Domínguez, 2005).

En cuanto a Colombia se podría considerar que reconoce ciertos DDHH de tercera generación como fundamentales, al ya estar incorporados en la Constitución. Por ejemplo, con el Artículo 22 que menciona el derecho a la paz y la obligatoriedad de su cumplimiento. También se debe señalar que, como se ha podido evidenciar, el concepto de DDHH de tercera generación es dinámico, puede modificarse y está en construcción permanente (Alcalde, 2018).

En beneficio de la objetividad hay que considerar el otro lado de la moneda, en este caso el derecho que tienen las farmacéuticas, y las empresas en general, como titulares de las patentes, cubierto por el Derecho Comercial Internacional (también denominado Derecho Mercantil Internacional) y por el Derecho Internacional Privado, dentro de los cánones del libre comercio, así como por el derecho a la propiedad intelectual; en el caso de derechos de patentes las organizaciones encargadas de su regulación son la Trade Related Aspects of Intellectual Property Rights-TRIP (Aspectos de los Derechos de Propiedad Intelectual relacionados con el Comercio) y la Organización Mundial del Comercio-OMC, desde 1995 (Peiró, López y Ortún, 2021).

De igual manera, las grandes farmacéuticas aducen que el problema no es tanto liberar las patentes en su calidad de derechos de explotación exclusiva para proteger e incentivar la innovación, sino que el quid radica en que no existe la capacidad de producción suficiente, así que no valdría compartir patentes si no hay laboratorios suficientes para producirlas, siendo esta afirmación un poco sesgada pues países como Canadá, México y Brasil tienen las instalaciones e infraestructura suficientes y adecuadas para esta tarea (OPS, 2021).

Actualmente sólo pueden producir las vacunas contra el Covid-19 aquellos países que tengan las patentes de las 10 vacunas que hay actualmente (con corte a finales de marzo de 2021), impidiendo el 
acceso y distribución equitativos de las mismas, frente a lo cual la OMS pidió al consejo de seguridad de la ONU que elimine, al menos temporalmente la propiedad intelectual de la vacuna para que la puedan producir otros laboratorios que tengan la capacidad de hacerlo. La respuesta fue un no rotundo de los países más desarrollados, quienes dicen que un levantamiento de las patentes desalentaría la inversión privada en innovación en una industria que mucho antes de la aparición del Covid-19 ya contaba con ganancias multimillonarias, y pasando por alto que gran parte de la investigación que se viene realizando sobre las vacunas contra el Covid-19 es auspiciada y financiada con dineros del sector público, principalmente de Estados Unidos y Europa, a cambio de lo cual tuvieron acceso a dosis suficientes para vacunar a toda su población, incluso hasta seis y siete veces.

Nos encontramos en este punto en una encrucijada donde hay argumentos sólidos que validan ambas posiciones, de una parte: el interés general, el bien común, la salud mundial, los DDHH de tercera generación, la primacía del valor de la vida por sobre los negocios; de otra: el derecho que protege a las actividades comerciales lícitas, el derecho a desarrollar la ciencia y la tecnología, el derecho a la propiedad industrial e intelectual, entre otros. Desde una perspectiva ética y moral por supuesto que no hay bien mayor que la vida y se debería llevar a cabo cualquier acción legal para protegerla, de igual manera el sentido común dicta que prima el bien general sobre el individual y que el logro de un bien mayor, como lo es la protección de la vida humana y el evitar millones de muertes por Covid-19, debería anteponerse a las ganancias económicas, sin embargo los intereses económicos que están en juego son enormes, por ejemplo Pfizer ha ganado con la vacuna contra el Covid-19 cerca de 3500 millones de dólares, y Moderna reporta beneficios netos de 1733 millones de dólares por la vacuna para el primer trimestre del presente año (Hooker y Palumbo, 2021) y, aunque pueda sonar cargado de cinismo en este caso, no se debe olvidar que el dinero mueve al mundo y permite que la sociedad continúe su marcha. 
Para concluir, se plantean algunas consideraciones que permitan tener un panorama más amplio acerca de la posibilidad de liberar la patente de las vacunas contra la Covid-19. Para empezar, urge positivizar los DDHH de tercera generación en general, y en el caso particular que corresponde a este trabajo, el derecho humano al uso de los avances de las ciencias y la tecnología para que se de igual ponderación a los derechos sociales que a los civiles y políticos, permitiendo entonces que se pueda vacunar rápida y gratuitamente a toda la población del planeta, a través de dicha positivación se cerrará la brecha existente entre la teoría doctrinal y los documentos vinculantes que permitan reivindicar tal derecho.

De igual manera debería plantearse la necesidad de un pacto consensuado liderado por organismos internacionales que cuenten con reconocimiento global, como la ONU y la OMS, que plantee una hoja de ruta en los casos de pandemias mundiales de carácter letal y de enfermedades que tengan la capacidad de afectar a grandes poblaciones, dicho protocolo podría aplicarse a los descubrimientos científicos liberándolos de las patentes buscando la realización de un bien mayor, como lo es el bienestar de la humanidad.

Si se considera desde el punto de vista económico se debe entender que el costo de tratar las pandemias resulta mayor, a mediano y largo plazo, que el costo de liberar las patentes; además el mundo no podrá sentir algo de alivio ante el Covid-19 y sus variantes y mutaciones hasta que se haya inmunizado a toda la población mundial, estableciéndose de paso el efecto de inmunidad de rebaño, es decir que nadie estará a salvo hasta que todos estén a salvo, como manifestó el investigador del Imperial College, Charlie Whittaker, a BBC News (Passarinho, 2021).

Una posibilidad hipotética diferente sería crear una especie de fondo común cooperativo al que aporten recursos las naciones con mayores ingresos, de manera similar a la iniciativa actual del Covax pero con un nivel de alcance mucho mayor, hoy en día Covax entrega vacunas apenas para el $20 \%$ de la población más desfavorecida (Fondo de las Naciones Unidas para la Infancia-UNICEF, 2021), además se necesitaría solventar problemas logísticos graves 
como demora en la entrega, el acceso a cualquier lugar del mundo y, por supuesto, la existencia de un stock de vacunas suficiente. Una variante de esta posibilidad podría ser que los costos de Investigación y Desarrollo, y los de producción para las vacunas sean sufragado por los Estados de manera que se potencien las capacidades nacionales e internacionales en estos campos y se logren resultados positivos más rápidamente y a un menor costo general.

Queda la esperanza de que como especie logremos reconocer pronto lo invaluable de la vida humana y se logre llegar a un acuerdo para valorar, aceptar y acatar por igual todos los derechos que le son reconocidos al hombre, independiente de su clasificación por generaciones, y zanjar las diferencias entre las diferentes ramas del Derecho llegando a un acuerdo que beneficie a todos, a corto plazo, y facilite la continuidad de los hombres sobre el planeta a mediano y largo plazo.

\section{Conclusiones}

La pandemia de Covid-19 cambió al mundo de diversas maneras e hizo patente la precariedad del sistema de salud existente, tanto internacional como nacionalmente, el proceso de vacunación que se está llevando a cabo en el mundo avanza a paso muy lento y no hay seguridad de que se pueda vacunar a toda la población, esto en gran medida debido a la negativa de liberar las patentes de las vacunas contra el virus por parte de las grandes farmacéuticas y de la Organización Mundial del Comercio, ya que, de una parte, las ganancias económicas son fabulosas y, de otra, hay compromisos legales que no se pueden evadir.

Lo anterior pese a que existen unos DDHH que tienen que ver con el derecho al uso de los avances de la ciencia y la tecnología, recordemos que los $\mathrm{DDHH}$ han ido refinándose y haciéndose más puntuales en respuesta a los cambios que experimentan las sociedades, ocurriendo entonces una clasificación de los DDHH en generaciones: la primera generación abarca los derechos civiles y político, la segunda compete a los derechos económicos, sociales y culturales, y, la tercera aborda los derechos de los pueblos, también 
llamados de solidaridad; estas generaciones se corresponden cronológicamente con los siglos XV-XVII, XVIII-XIX, y XX-XXI, respectivamente.

Dentro de los DDHH de tercera generación, los cuales reivindican los derechos de los pueblos y a la solidaridad, se encuentra el mencionado derecho a usufructuar los avances en cuanto a ciencia y tecnología, no obstante, los DDHH de segunda y tercera generación no tienen carácter vinculante, de cierta manera existen cuestionamientos sobre la titularidad de los mismos pues no está totalmente claro si son derechos individuales o colectivos ni sobre quién recae la titularidad. En líneas generales se le da mayor consideración legal y jurídica a los DDHH individuales, es decir a los civiles y políticos, que a los DDHH colectivos, como lo son los sociales y los de solidaridad.

A pesar de los intentos por subsanar estas anomalías, como por ejemplo la justiciabilidad de los DDHH o la búsqueda de una unicidad generacional de los mismos, no se han logrado positivizar estos $\mathrm{DDHH}$, quedando plasmados en el papel pero sin acciones reales que las materialicen, así sucede con el acuerdo para liberar las patentes de las vacunas, en un pulso que por ahora ganan las farmacéuticas respaldadas por los países que se niegan a dicha liberación, bien por motivos económicos, políticos, geopolíticos y biopolíticos.

Esta brecha entre lo propuesto sobre DDHH de tercera generación y su aplicabilidad real afecta a la población mundial en general, siendo los más perjudicados con la pandemia actual precisamente los grupos más vulnerables quienes requieren mayor solidaridad y apoyo, es así como para el año 2021 el Banco Mundial (2020) prevé que el Covid-19 y la recesión económica ocasionada por el virus llevará a la pobreza a cerca de 150 millones de personas, es decir tendrán que vivir con menos de dos dólares al día; la justiciabilidad y positivización de los DDHH de tercera generación, entre ellos el derecho a disfrutar de los adelantos científicos y tecnológicos, no sería una panacea, sin embargo permitiría mejorar en gran medida las condiciones y la calidad de vida que soportan muchos los más vulnerables en el planeta. 
Queda, entonces, pendiente la tarea de llegar a consensos, de una larga batalla jurídica, legal, social, política y cultural para lograr positivizar los DDHH de segunda y tercera generación, en búsqueda de que los derechos humanos sean realmente lo que su nombre indica, que tengan la calidad de derechos universales, indivisibles, interrelacionados para toda la humanidad.

\section{REFERENCIAS}

Alcalde, S. (2018). El derecho de libre determinación de los pueblos. Un derecho humano de tercera generación en el nuevo constitucionalismo latinoamericano [Tesis Doctoral]. UNED, Madrid, España. Disponible en http://e-spacio.uned.es/fez/ view/tesisuned:ED-Pg-DeryCSoc-Salcalde

Alé, M. (2021). Colisión de derechos en pandemia.Derecho a la salud y límites a la acción estatal. Jurídicas CUC, 17(1), 367404. http://dx.doi.org/10.17981/juridcuc.17.1.2021.13

Amnistía Internacional. (febrero 19, 2021). Las naciones del G-7 se perjudican a sí mismas al no garantizar el acceso global a las vacunas. [Comunicado de prensa]. Disponible en https:// www.amnesty.org/es/latest/news/2021/02/g7-leaders-areshooting-themselves-in-the-foot-by-failing-to-tackle-globalvaccine-access/

Bailón, M. J. (2009). Derechos humanos, generaciones de derechos,derechos de minorías y derechos de los pueblos indígenas; algunas consideraciones generales. Derechos Humanos México. Revista del Centro Nacional de Derechos Humanos, 4(12), 103-128. Recuperado de https://revistascolaboracion.juridicas.unam.mx/index.php/derechos-humanos-cndh/article/view/5683/5020

Banco Mundial. (octubre 7, 2020). Debido a la pandemia de COVID-19, el número de personas que viven en la pobreza extrema habrá aumentado en 150 millones para 2021. [Comunicado de prensa]. Disponible en https://www.bancomundial.org/es/news/press-release/2020/10/07/covid-19-toadd-as-many-as-150-million-extreme-poor-by-2021 
Bidart, G. (1996). Manual de la constitución reformada. Buenos Aires: Ediar.

Bonet, A. (2016). Consecuencias de la clasificación de los derechos humanos en generaciones en relación a la justiciabilidad de los derechos sociales. Revista de la Facultad de Derecho y Ciencias Politicas - UPB, 46(124), 17-32. http:// dx.doi.org/10.18566/rfdcp.v46n124.a02

Bonilla, O. A. (2020). Para entender la COVID-19. Medicentro Electrónica, 24(3), 595-629. Recuperado de http://www. medicentro.sld.cu/index.php/medicentro/article/view/3214

Castro-Sardi, X., Cagüeñas, D., Quintero, D. P., Frenández, J. y Silva, R. (2020). Ensayos sobre la pandemia. Cali: ICESI. Disponible en https://www.icesi.edu.co/editorial/pandemial

Cassagne, J. C. (2019). Los nuevos derechos y garantías. Revista de Investigaciones de la Constitución, 3(1), 59-108. Disponible en https://revistas.ufpr.br/rinc/article/view/45110

CNDH. (2015). Clasificación de los Derechos Humanos en tres generaciones. [Online]. Recuperado de https://salud3.guanajuato.gob.mx/cgayf/admin/CGAF/Dir\%20General\%20 de\%20Administracion/2015/Control\%20Interno/CNDH/ Descargables/historia_2_5.pdf

COE. (2015). Manual de Educación en los Derechos Humanos con jóvenes. Madrid: Compass. Disponible en https://www.coe. int/es/web/compass/home

Domínguez, C. (2005). Los llamados derechos de tercera generación. [Trabajo de Seminario para grado]. Universidad Autónoma de Chile, Santiago de Chile, Chile.

Fischer-Lescano, A. \& Möller, K. (2012). Der Kampf um globale soziale Rechte: Zart wäre das Gröbste. Berlín: Wagenbach.

García, A. (2012). Aspectos éticos de la investigación en educación médica. Investigación en Educación Médica, 1(1), 28-34. Recuperado de http://riem.facmed.unam.mx/node/178 
García, M. y Reyes, J. (2014). Desafíos de las tecnologías de la información y derechos humanos. Revista Iberoamericana de las Ciencias Sociales y Humanísticas, 3(5), 44-64. Disponible en https://www.ricsh.org.mx/index.php/RICSH/article/view/23

Golçalves, R. (agosto 26, 2020). La protección de derechos humanos en tiempos de COVID-19. UNIR. Disponible en https:// www.unir.net/derecho/revista/proteccion-derechos-humanos-covid/

Gómez, Y. (2004). Estado constitucional y protección internacional. En Y. Gómez, Pasado, presente y futuro de los derechos humanos (pp. 231-280). México, D.F.: CNDH.

González, O. (2018). Derechos humanos y derechos fundamentales. Hechos y Derechos, (45), 13-15. Disponible en https://revistas.juridicas.unam.mx/index.php/hechos-y-derechos/article/view/12556/14135

Hooker, L. y Palumbo, D. (mayo15, 2021). Vacunas contra el coronavirus: cuánto dinero pueden ganar realmente las farmacéuticas con la inmunización. BBC News. Disponible en https://www.bbc.com/mundo/noticias-55293057

IDHC. (2009). Proyecto de carta de Derechos Humanos Emergentes. [Monografía]. Recuperado de https://catedraunescodh. unam.mx/catedra/catedradh2007/SeminariosCatedra/Documentos/CartaDerechosEmergentesDH.pdf

IIDH. (2009). La justiciabilidad directa de los derechos económicos, sociales y culturales. San José: SIDA. https://www.iidh. ed.cr/IIDH/media/1467/justiciabilidad-directa-desc-2009. pdf

INTEF. (2015). Las tres generaciones de derechos. Ética y derechos. Disponible en http://recursostic.educacion.es/secundaria/edad/4esoetica/quincena5/quincena5_contenidos_5. htm\#: :text=La\%20primera\%20generaci\%C3\%B3n\%20 incluye $\% 201$ os $\% 20$ derechos $\% 20$ civiles $\% 20$ y $\% 20$ pol\%C3\%ADticos.\&text=Algunos\%20derechos\%20 pol\%C3\%ADticos\%20fundamentales\%20son 
Jaramillo, M. E. (enero 20, 2021). La pandemia contra los pobres: COVID19, más frecuente en colonias con menor desarrollo social de la CDMX. Animal politico. Disponible en https:// www.animalpolitico.com/el-ronroneo/la-pandemia-contralos-pobres-covid19-mas-frecuente-en-colonias-con-menordesarrollo-social-de-la-cdmx/

JHU. (s.f.). COVID-19 Dashboard by the Center for Systems Science and Engineering (CSSE) at Johns Hopkins University (JHU). [Online]. Disponible en https://coronavirus.jhu.edu/ map.html (consultada febrero 22, 2021)

Lolas, F. (2020). Perspectivas bioéticas en un mundo en sindemia. Acta bioethica, 26(1), 7-8. Recuperado de https://actabioethica.uchile.cl/index.php/AB/article/view/57347/60832

Marcus, M. (enero 20, 2021). Ensuring Everyone in the World Gets a COVID Vaccine. Duke Global Health Institute. Disponible en https://globalhealth.duke.edu/news/ensuring-everyone-world-gets-covid-vaccine

Mendoza, F. R., Bechara, A. Z. y Caballero, J. (2021). La intimidad como derecho humano y la solidaridad como valor constitucional en la era del Covid-19. Jurídicas CUC, 17(1), 277298. http://dx.doi.org/10.17981/juridcuc.17.1.2021.10

Moyn, S. y Jácome, J. (2015). La última utopía : Los derechos humanos en la historia. Bogotá, D.C.: Pontificia Universidad Javeriana. Disponible en https://repository.javeriana.edu. co/handle/10554/44688

Nikken, P. (2010). La protección de los derechos humanos: haciendo efectiva la progresividad de los derechos económicos, sociales y culturales. Revista IIDH. (52), 55-140. Recuperdado de https://www.corteidh.or.cr/tablas/r25563.pdf

OEA. (2021). Proyecto de Resolución "Distribución equitativa de vacunas contra la Covid-19". [A/Ser.G]. Recuperado de http:// scm.oas.org/doc_public/SPANISH/HIST_21/CP43475S06. docx 
ONU. (febrero 17, 2021). Diez países han acaparado el 75\% de las vacunas COVID-19 administradas, denuncia Guterres al Consejo de Seguridad. [NewsONU]. Disponible en https:// news.un.org/es/story/2021/02/1488202

ONU. ACNUDH. (2013). Declaración y programa de acción de Viena. 1993-Conferencia Mundial de Derechos Humanos. [1336163-DPI/1394 Rev.2]. Recuperado de https://www.ohchr. org/documents/events/ohchr20/vdpa_booklet_spanish.pdf

ONU. (1948). Declaración Universal de los Derechos Humanos. [Resolución 217 A (III)]. Disponible en https://www.un.org/ es/about-us/universal-declaration-of-human-rights

ONU. (1945). Carta de las Naciones Unidas. ONU. Disponible en https://www.un.org/es/about-us/un-charter/preamble

OMS. OPS. (mayo 19, 2021). Directora de OPS llama a cerrar las brechas de acceso a vacunas COVID-19 ampliando su producción en América Latina y el Caribe. OPS. Disponible en https://www.paho.org/es/noticias/19-5-2021-directora-opsllama-cerrar-brechas-acceso-vacunas-covid-19-ampliando$\mathrm{su}$

OMS. OPS. (2020). ¿Qué es el coronavirus? Paho. Disponible en https://www.paho.org/es/temas/coronavirus

Oxfam International. (enero 20, 2020). Los milmillonarios del mundo poseen más riqueza que 4600 millones de personas. Oxfam. Disponible en https://www.oxfam.org/es/notasprensa/los-milmillonarios-del-mundo-poseen-mas-riquezaque-4600-millones-de-personas

Passarinho, N. (marzo 26, 2021). Coronavirus: cómo el mundo puede acabar dividido en dos según el riesgo de covid-19. $B B C$ News. Disponible en https://www.bbc.com/mundo/noticias-56527963

Pinilla, M., Ramírez, A. y González, C. (abril 7, 2020). Los pobres, los más afectados por la pandemia. UniAndes Colombia. Disponible en https://uniandes.edu.co/es/noticias/salud-ymedicina/los-pobres-los-mas-afectados-por-la-pandemia 
Peiró, S., López, B. y Ortún, V. (mayo 10, 2021). ¿Es la solución liberar las patentes de las vacunas COVID? The Conversation. Disponible en https://theconversation.com/es-la-solucion-liberar-las-patentes-de-las-vacunas-covid-160549

Rodríguez, J. H. (2015). La evolución de los derechos humanos en el sistema penal colombiano: la materialización de la dignidad humana y el debido proceso una mirada desde 1789. [Tesis Grado]. Universidad Libre de Colombia, Bogotá, D.C., Colombia. Disponible en https://repository.unilibre. edu.co/handle/10901/9364

Sánchez, R. (2001). Generaciones de derechos y evolución del Estado. En Y. Gómez, Los derechos humanos en Europa (pp. 49-61). Madrid: UNED.

Statista. (s.f.). Muertes por covid-19 en el mundo. Statista. Disponible en https://es.statista.com/buscar/?q=muertes+por+covi $\mathrm{d}+19+$ en+el+mundo\&qKat=newSearchFilter\&sortMethod $=$ idrelevance\&language $=0 \&$ isRegionPref $=170 \&$ statistics $=$ $1 \&$ accuracy $=$ and\&isoregion $=0$ \&isocountrySearch=\&categ ory $=0 \&$ interval $=0 \&$ archive $=1$ (consultado en 2021 )

Trula, E. (febrero 1, 2021). Un sálvese quien pueda: así está fracasando el plan para que los países ricos compren vacunas a los pobres. Magnet. Disponible en https://magnet.xataka. $\mathrm{com} /$ preguntas-no-tan-frecuentes/salvese-quien-pueda-asiesta-fracasando-plan-paises-ricos-compren-vacunas-a-pobres

Twohey, M., Collins, K. y Thomas, K. (diciembre 17, 2020). Los países prósperos aseguraron sus vacunas, pero 'han vaciado los estantes' para el resto. The New York Times. Disponible en https://www.nytimes.com/es/2020/12/17/espanol/ vacunas-paises.html

UNICEF. (mayo 25, 2021). Mecanismo COVAX: vacunas contra la COVID-19 para todos. Unicef. Disponible en https://www. unicef.es/noticia/mecanismo-covax-vacunas-contra-la-covid-19-para-todos 
Wallace, S. (agosto 6, 2020). Los pobres e indígenas tienen más probabilidad de morir si se enferman de COVID-19, advierte la OMS. NewsONU. Disponible en https://news.un.org/es/ story/2020/08/1478482

* El presente artículo hace parte del proyecto de grado de la Maestría en Derechos Humanos y Conflicto Interno Armado dentro de la línea de investigación: Memoria Histórica, Memoria Institucional, Derechos Humanos, DICA y justicia de la Escuela Superior de Guerra

María Cristina Ramírez Castiblanco es Maestranda en Derechos Humanos y Conflicto Interno Armado de la Escuela Superior de Guerra. Abogada de la Universidad Autónoma de Colombia, especialista en Derecho Penal y Criminología de la Universidad Autónoma de Colombia, con maestría en Derecho Penal de la Universidad Libre de Colombia. https://orcid.org/0000-0003-2918-5056 